\title{
Transforming Health Care by Transforming Ourselves
}

\author{
Mary Elizabeth Bathum* \\ Department of Nursing, Henry Predolin School of Nursing, USA
}

*Corresponding author: Mary Elizabeth Bathum, Department of Nursing, Henry Predolin School of Nursing, USA.

Received Date: August 27, 2019

Published Date: September 25, 2019

\section{Short Communication}

At a recent nursing conference, an experienced nurse stood up in the audience and asked to address the nursing students in the room. She graciously thanked them for their participation and then gave them striking advice, "The most important thing you will need to learn if you are going to thrive in nursing is how to put your selfcare above everything else".

The practice of Nursing is becoming more and more challenging. An ever-changing health care system leaves us wondering week by week what our resources are going to be, how our employment, positions, and workload may shift and how legislative policy changes are going to affect how we can best care for our patients and clients. Increasingly, we care for complicated patients with multiple co-morbidities deeply affected by poverty and social inequalities. We question our practice when we are forced to discharge them to inadequate social situations, then are blamed when they are readmitted.

It is no wonder that newly graduated nurses leave nursing at such alarming rates. A study of policy and nursing practice reveals that an estimated one in five (17.5\%) of newly licensed RNs leave their first nursing job within the first year, and one in three (33.5\%) leave within two years. The average turnover rate for bedside nurses in 2016 was 17.2\% National Healthcare Retention, [1]. This rapid turnover has a high cost in morale and workload, but also carries a high financial cost for organizations. The average cost of turnover for a bedside registered nurse ranged from $\$ 36,900$ to $\$ 57,300[2]$.

We recognize that more and more nurses experience a disengagement from their work or report compassion fatigue with detrimental costs not only to themselves but also to the health care system. A disengaged nurse's behavior decreases productivity by complaining to others, performing work with a less-than-optimal attitude, calling in sick, taking longer to complete routine tasks, and failing to go beyond when needed. This has a high cost in unit morale but also has a financial cost to our organizations.

Harris \& Griffin [3] reported that nurses experiencing compassion fatigue often have a decline in personal health, exhibit inadequate nursing performance, make medical errors and mistakes related to poor judgement and decreased discernment, and decrease the quality of patient care and patient dissatisfaction. Chronic absenteeism, high workers' compensation costs, high turnover rates, and interpersonal conflicts can be prevalent in compassion-fatigued nurses. How can we, as a nursing profession, transform our health care system to be a place of health for our patients and ourselves?

Transformation [4], in an organizational context, is a process of profound and radical change that orients an organization in a new direction and takes it to an entirely different level of effectiveness. Transformation implies a basic change of character and little or no resemblance with the past configuration or structure [4]. To change our health care system in a radical and profound way, we, as nurses, need to change ourselves. I am convinced that teaching, mentoring and modeling self-care to nursing students is an essential way to foster this transformation.

For the past eight years, a course in our integrated studies program at Edgewood College entitled "Caring for Ourselves as We Care for the World" has offered students an opportunity to explore the connections between their life work as helping professionals and their development as leaders in these careers with building resilience through self-care, self-inquiry and mindfulness. Part of their integrated studies requirement, students in nursing, criminal justice, social work, education, music and art therapy and lately in computer sciences and business participate in a weekly class where basic tenets of mindfulness, meditation, body and emotional awareness, self-inquiry, self-compassion and self-care are taught 
and practiced. Students must then practice these skills each week in their professional student fieldwork and reflect in journals and classroom discussions their usefulness in their present and future work to increase their resiliency. Through readings, discussion, and service activities students reflect upon community experiences, how these experiences influence their personal and public worlds, and their personal values in relation to these spheres, while identifying and examining their own value systems as they are situated in the values systems of other contexts. For many students, it is the first time they have taken the time to delve into inner work and self-exploration and their reflections, offered here, have been insightful and hopeful.

"When it comes to applying mindfulness to my field experiences, I feel like it helped wonders. This was difficult for me because I have never worked with people with disabilities before, but I was able to exercise patience and compassion the entire time. There was no need to let myself get worked up because the people I was helping could not control it themselves, and because of that there is no reason they should be rushed or patronized"

"Being a nurse, you are constantly running around, hardly getting any time to relax, so making time before and using the quick methods before has already benefited me and hope to benefit me more once I become an actual RN with a full patient load. If you are not focused on your patient and in the moment, you could do something either too fast, not correct, etc. and can really affect someone's health".

"By practicing mindfulness, we are reminded that although there is an illusion that we all live separate lives, our stories and experiences in this world are very much intertwined. So, in other words, my health and wellness will have a direct effect on the health and wellness of society as a whole".

"Mindfulness and meditation have helped me be more aware of my own needs. I have come to understand that taking care of myself is not selfish, but rather it allows me to take better care of others. When I am calm, rested, and present, I am able to give my patients better quality care".

Self-compassion is important to explore because it influences how you respond to the people around you. You cannot care for others without first taking care of yourself. Self-compassion influences me very regularly in the clinical setting. It was interesting to me because I have never before thought of compassion in this way".

"By centering my thoughts and taking time for meditation, I am able to gather the energy necessary to heal those around me. This is an essential part of nursing. To keep my mindfulness practice going, I intend on planning a specific time every single day for silence. I am excited to see how mindfulness transforms me throughout the rest of my nursing career!"

When I began promoting teaching self-care to nursing students as an essential tool to help transform our health care system, an experienced and "crusty" older nurse educator said to me, "we should not spend time on self-care as there is so much nursing students need to learn about patient care". I agree that there is so much students need to learn to care for patients, but there is no dichotomy here. Self-aware, self-compassionate and self-motivated nursing students will remain engaged employees, will have the resilience to prevent compassion fatigue, and will improve patient care.

Jon Kabat Zinn [5], who helped bring the practice of mindfulness to health care and health care workers, states this so, well: "The journey towards health and sanity is nothing less than an invitation to wake up to the fullness of our lives as if they actually mattered. It turns out that we have, lying deep within us, in our hearts and in our very bones, a capacity for a dynamic, vital, sustaining inner peacefulness and well-being. When we mobilize and refine that capacity and put it to use, we are much healthier, physically, emotionally and spiritually".

Fully awake and aware nurses will transform our health care system!

\section{Acknowledgement}

I would like to thank my undergraduate and graduate students for their thoughts, questions, challenges and scholarship that motivated me to write this article.

\section{Conflict of Interest}

Author Declare no conflict of interest.

\section{References}

1. 2019 National Healthcare Retention and RN staffing report. In: Nursing Solutions, Inc.

2. Dempsey C, Reilly B (2016) Nurse engagement: What are the contributing factors for success? OJIN 21(1).

3. Harris C, Griffin TQ (2015) Nursing on Empty: Compassion Fatigue Signs, Symptoms, and System Interventions. J Christ Nurs 32(2): 80-87.

4. Transformation (2017).

5. Kabat Zinn J (2005) Coming to our senses: Healing ourselves and the world through mindfulness. London: Piatkus. 